\title{
The Degree of Application of Educational Administrative Accountability by the Principals of Special Education Centers and its Relationship to Some Variables from Teachers' Perspective
}

\author{
Aziz Ahmed Al-Rahamneh \\ Salt Faculty of Human Sciences, \\ Department of Educational Sciences, \\ As-Salt, Jordan
}

DOI: https://doi.org/10.36941/jesr-2022-0014

\section{Abstract}

This study aimed to define the degree of application of educational administrative accountability by the principals of special education centers and its relationship to some variables from the teachers' perspective in Amman. The descriptive-analytical approach was adopted. The study sample consisted of (85) male and female teachers, who were chosen randomly. A measure of administrative accountability in educational systems was developed consisting of four areas namely, students, teachers, goals, innovation, and creativity. Findings revealed that the degree of application of educational administrative accountability by the principals of special education centers came to a medium degree and in all its fields, and there were no differences in the degree of application of educational administrative accountability by the principal of special education centers attributed to the variables of gender and educational level.

Keywords: Educational administrative accountability, special education centers

\section{Introduction}

Any educational institution's performance is dependent on its leadership, and to attain the desired educational goals, an effective, purposeful, and developed administration is required. However, the core of administration is based on the good investment of both human and material resources because through them the desired goals can be achieved with the least amount of effort, at the lowest cost, and in the shortest amount of time. Advocacy was raised for adopting new leadership patterns that encourage collaborative work, participation in decision-making, and focusing on and promoting the development of other employees. In addition to abandoning the traditional concepts of leadership that are based on guardianship, hierarchy, and authority of the center, under a framework in which the quality of the organization's production and performance coincides and caring for its employees.

Administrative accountability is of great interest to educators, because of the tremendous changes and development in various fields that have brought about a major change in the educational system. Therefore, it was necessary to find a system that raises educational outcomes to 
keep pace with this tremendous development, and it was the educational accountability system (Abu Hamda, 2008).

The proper educational system is a crucial foundation for building the new generations, since the success or failure of this system is tightly linked to the success or failure of other departments, and therefore, this system must have a great and constant follow-up to identify its strengths and weaknesses and be subject to periodic supervision to determine the progress of Work, and the extent to which it keeps pace with the changes and developments that occur continuously in the various areas of life (Abu Hamda, 2008). Several efforts have been made to reform the educational system by developing school administrations, which are directly responsible for implementing educational programs and achieving the required educational outcomes. Which calls for the practice of educational accountability regularly to achieve the most appropriate and successful way for the educational process, thus achieving the aspirations of the members of these institutions (AlHammoud, 2007).

Educational accountability is a requirement for all segments of the society since it ensures that educational systems achieve the expectations of the community, especially since many questions arise about the adequacy and effectiveness of the outputs of educational systems and their ability to build high knowledge frameworks, an appropriate value system, positive trends and unique skills for students. This fact led to the emergence of educational accountability, which is concerned with the commitment of those in charge of the educational process to continuously provide evidence and explanations for the learning outcomes that are presented within the educational institution (Kaspari, 2003). The researcher was interested in researching accountability despite the presence of a small amount about the concept in the Arab educational and non-educational literature, and the reason for this scarcity is that accountability is still at its outset(Al-Omari, 2004), and although the interest in accountability has recently emerged, especially in the educational field, however, it is considered a very old idea which based on the fact that an individual assigned to perform a certain task according to specific conditions and then he held accountable for the products of this performance. Its significance emerges as a means of following up on the work of subordinates, and an entry point to ascertain how the actual performance is, and to form ideas on how to perform the most appropriate way. Those working in this system through transparent dealing with all components of the system and its performance (Akhuirsheed, 2006).

\section{Study problem and Questions}

Administrative accountability issues have been linked to accountability systems. This prompted the creation of flexible accountability systems that consider the needs of those affected by the educational system to obtain an accountability system that satisfies expectations with the fewest possible complications. Among the problems related to administrative accountability systems are defining goals, determining who is responsible for educational outcomes, putting pressure on teachers, staff, and administrators, and accepting administrative accountability and its potential negative effects. Furthermore, some problems are related to defining and measuring outputs, setting priorities for previous responsibilities, pressures to create an accountability system to measure the extent to which management achieves the needs of innovation and renewal, and negative trends towards administrative accountability (Al-Zoubi, 2003).

Obstacles to accountability systems include changing the scale and goal, lack of patience to know what has been accomplished and then building on it, and speed in judging programs. The researcher noted that some of the teachers of special education centers have negative attitudes towards the issue of administrative accountability and the problems of its application, and they do not realize that its benefits are much greater than the negatives. It's also worth noting that educational accountability can fall short if conditions aren't addressed in which roles and expectations are clear, feedback is accessible and connected, and accountability methods are reviewed and scrutinized. Also, one of the most important justifications that called for the need for 
an accountability system in educational systems is the increasing feeling on the part of parents of the need to pay more attention to the education of their children, especially those with autism disorder and students with other disabilities, as well as their growing awareness of the role of accountability as a controlling factor for quality, efficiency and good performance, and attention Educators evaluate the outcomes of the learning and teaching processes, especially with the development in educational technology that helps measure the outcomes of the educational system. Accordingly, the problem of the study is to evaluate the role of the principals of special education centers concerned with autism in Jordan in applying administrative accountability according to the educational systems. The study questions are summarized as follows:

1. What is the degree of application of educational administrative accountability by the principals of special education centres from the teachers' perspective?

2. Are there statistically significant differences in the degree of application of educational administrative accountability by the principals of special education centres attributed to the variables gender and educational level?

\subsection{Study Importance}

The study's significance is emphasized on the concept of administrative accountability in educational systems, and its role in improving job performance among individuals working in special education centers, and to increase awareness among them of the concept of accountability, its importance, objectives, and the benefits of activating it, to emphasize that it is not a mean of punishment but rather than a tool for improvement. However, the study stems its importance from two aspects:

\subsubsection{Theoretical importance}

1. The importance of the subject of the study in dealing with all variables.

2. Its results consider the development and design of training programs for the administrations of special education centers on the importance of administrative accountability in educational systems.

3. It opens the way for future studies in this field, depending on the results that will be reached and the recommendations it will present.

\subsubsection{Practical Importance}

1. Contributing to enriching one of the important areas in the field of administrative studies, which is administrative accountability.

2. Drawing the attention of officials to the importance of revealing them and directing their administrative practices in this light.

\subsection{Study Objectives}

The current study aimed to clarify the concept of administrative accountability in educational systems, demonstrating the degree to which educational administrative accountability is applied by special education center principals from the perspective of teachers, and determining whether there are statistically significant differences in the degree to which educational administrative accountability is applied by special education center principals attributable to the variables gender and academic level. 


\subsection{Definitions}

Educational administrative accountability: This is a method of monitoring educational personnel and how they use the powers, authorities, and responsibilities assigned to them to ensure that all educational system inputs, activities, and outputs are operational (Al-Derini, 200o). Procedurally it is defined as the degree to which the participants will obtain through their response on the educational administrative accountability scale developed by the researcher.

Special Education Centers: They are centers that provide educational programs and services for people with autism disorder in the Hashemite Kingdom of Jordan (Al-Khatib et al., 2013).

\subsection{Limitations of the study}

It consisted of the following:

1. Human limits: special education centers.

2. Spatial limits: Jordan / Amman.

3. Time limits: the year 2020.

4. Objective limits: The degree of application of educational administrative accountability by the principals of special education centers from the teachers' perspective.

The generalization of the results depends on the degree of representation of the sample to the study population, the study tools, its dimensions, and psychometric properties.

\section{Theoretical Framework}

\subsection{Educational Accountability}

The concept of educational accountability is one of the modern concepts adapted by the educational systems, and it has been associated with other concepts such as accounting, evaluation, or follow-up. Accountability in the modern educational system dates back to the eighties of the last century when educational accountability in the United States and the United Kingdom was limited to primary and secondary education, as stated in the scientific encyclopaedia of Education, and it is later extended to the higher education system (Touq, 1997). Educational accountability eliminates the manifestations of nepotism in the administration, if any, and contributes to pushing it towards balance, stability in work according to the merit system, the values of justice and equal opportunities, and prioritizing the public interest over private interest (Hwail, 2012).

Numerous studies have examined the issue of administrative accountability in the educational system, such as the study of (Al-Derini, 2000) confirmed that the attitudes of secondary schools towards accountability in the capital, Amman, Jordan, were positive, in addition to differences in their attitudes attributed to the variable of gender and type of school. Al Rasbi (2006) cited that the estimates of department heads in the directorates of education, educational supervisors, and school principals in the Sultanate of Oman regarding the degree of application of the elements of accountability in performance came to a high degree in the areas of the reporting system on educational results and job description, whereas the fields of educational goals, standards, and evaluation system obtained a medium degree. Improving the administrative accountability system in educational institutions is required to achieve fairness and objectivity, as well as to raise the satisfaction of workers in these institutions with their work and contribute to improving the effectiveness of the system (Fillet and Abdel-Majeed, 2005). When accountability is effectively applied, it reduces waste of resources and administrative corruption. Indeed, it is a requirement for setting norms for ethical practice, evaluating and developing performance, assuring continuous progress, and examining the institution's strengths and weaknesses (Tarkhan, 2006). Accountability, as seen by (Madaus, 200o), is for the boss to hold subordinates accountable for the work they perform, and to notify him of the level of this performance through an evaluation process based on 
clear criteria and consistent with agreed goals. It is defined by (Batah, 2006) as the outcome of the educational process through which an educational program is evaluated in terms of its effectiveness and efficiency in achieving student learning, and educators are responsible for the failure or success of the educational program. Administrative accountability is also defined as the president holding the subordinate accountable for the work he performs, and notifying him of the level of this performance, through the evaluation of these actions (Al-Taweel, 2006). Hence, oversight and accountability are concerned with following up on each of these activities to assess the organization's progress toward its objectives. They are two renewable functions that verify that performance is carried out as defined by established objectives and standards by evaluating and modifying the degree of success of actual performance in meeting the goals and standards (Thabet, 2008).

Fort and Hebbler (2004) defined it as a systematic method of assuring those inside and outside the educational system that schools and students are moving toward desired goals. Al-Harith (2005) defined it as the commitment of education personnel to provide answers or explanations for the learning outcomes they provide, to ensure the activation of all educational system inputs, processes, and outputs .It describes the outcome of the educational process through which an educational program is evaluated in terms of its effectiveness and efficiency in achieving student learning, and educators are responsible for the failure or success of the educational program (Batah, 2006). It's also defined as the involvement of educational system elements (human and non-human inputs, processes, and outputs), as well as other formal and informal segments of society, in determining educational outcomes and attaining educational goals, such as student learning goals, and then conduct an organized evaluation to ensure those goals, because it depends on rewards and penalties (Al-Omari, 2012).

Hill \& Robin, referred to in (Batah, 2006), indicated that educational accountability aims at improving the educational level of schools, financing schools according to their needs, providing real reports on student achievement levels, classifying schools, and rewarding high levels. In addition to improving the conditions of low-level schools, restructuring schools that repeatedly failed to achieve the level of their students, and re-arranging and distributing responsibilities to the administrative departments in the districts (Batah, 2006).

Accountability should be considered as a method for reviewing and improving performance, as well as developing the skills of educational staff, and not as a source of fear and anxiety, nor as a tool for threat, as the positive and effective practice of educational accountability has several benefits, which can be summarized in the following (Batah, 2006):

- Through accountability, the overall energy of the educational institution is focused on its strategic objectives.

- It leads to coordinating the efforts of teams and individuals in the educational institution.

- It identifies performance gaps and works to fix them.

- Strengthen forms of support and partnership among members of the educational community.

- Provides employees in the educational institution a clear picture of the expected and desired results of their work.

- Supports strategic thinking at the level of individuals and groups.

- It promotes rational relations between managers and employees, in terms of each party's knowledge of its obligations and duties, and the required support, leading to the success of the educational institution in achieving its goals.

- It places greater emphasis on student learning outcomes.

- It gives more impetus to curriculum development.

- It raises the level of expectations, and thus raises the level of achievement.

- It urges educators to improve the methods used in teaching and assessment.

- It boosts the level of interest of all participants in the educational process, as well as those who influence it, and helps the teacher focus on student learning.

Several principles must be considered when approving the rules of accountability for educational administration, represented by the following (Akhursheid, 2006): 
- Clarity of the rules of the system and the consequences of violations: Workers must have a clear awareness of the rules to be adhered to, the consequences of violations, and the penalties imposed on violators.

- Direct implementation of the penalty: This principle refers to finding a link between the violation and the penalty so that the worker avoids it in the future, and there must be a sufficient investigation of the violation and its causes, the start of taking special measures, and the application of the penalty.

- The fairness of the application of the penalty: the workers must be convinced of the fairness of the application of the penalties to accept them without complaining. There must be a clear warning that a specific violation exposes the one who commits it to a specific penalty.

- Equality and homogeneity in the imposition of punishment: This principle is one of the most important principles of accountability when inflicting punishment, as the punishment is not related to the offending person, but is related to the type of violation, and the punishment is graded according to the frequency and type of the violation.

The role of the principal in the educational institution is to spread the culture of educational administrative accountability in two aspects:

1. The administrative aspects:

It comprises several roles in holding teachers accountable, as mentioned by (Al-Taweel, 1999):

- He appreciates their commitment to the council meetings that he organizes in the school.

- Promotes their participation in the daily supervision of students.

- Investigate their misuse of official working time.

- He reprimands them for not obeying his instructions and orders.

- Addresses their lack of work motivation.

- He reviews them for their irregularity in coming to work on appointments.

- He holds them accountable for the spread of indifference.

- Punish them for disclosing the confidentiality of senior management's correspondence and decisions, and investigate their non-compliance with school regulations, rules, and instructions.

- Motivates them not to leave school before the scheduled time.

- Punish who offend professional ethics will be punished.

- Submit to the officials a detailed report on the performance of the good and the negligent.

- Draws their attention to the lack of preference towards some students.

- Fights nepotism and bribery within the school.

- Investigate their use of corporal punishment with students.

2. The technical considerations: It has a variety of functions, as listed below (Abu Al-Wafa, 2008):

- He criticizes teachers for failing to create annual plans for the subjects they teach.

- Brings their attention to a shortcoming they have in lesson planning.

- He chastises them for their failure to adequately manage and organize the class.

- Directs teachers to start the lesson with an appropriate introductory activity.

- He holds them accountable for their shortcomings in studying and analyzing the prescribed curricula and books.

- He encourages them to develop their problem-solving abilities.

- He holds them accountable for their lack of commitment to the sequence of steps of the educational situation.

- He encourages them to connect the previous information with the new topic of the lesson.

- He rewards teachers for achieving set goals.

- He motivates them to use appropriate means of reinforcement in the learning process.

- He holds them accountable for their negligence in preparing various tests and exercises.

- He holds them accountable for their behavior that is inconsistent with the school's values.

The school principal must also spread the accountability culture, explain how it works, and 
prepare for it. One of the most important responsibilities of school leadership in this area is to guide the staff through the process of determining the appropriate educational practices to meet new expectations, as well as to coordinate all resources to meet the response to standards-based accountability. The leader must be aware of positive standards at a time when the school's values and culture must be preserved (Tarkhan, 2006).

Improving administrative accountability system standards in educational institutions is vital for achieving fairness and objectivity, as well as raising worker job satisfaction and contributing to improving the quality of workers' performance. As well as confirming the extent to which teachers and principals of special education centers have autism of scientific and practical knowledge. The current study aimed to identify the degree of application of educational administrative accountability by principals of special education centers and its relationship to some variables from the teachers' perspective.

\subsection{Previous studies}

Adelphia (2011) aimed to ascertain the degree of accountability among teachers in the management of secondary schools in Ethiopia, Nigeria. The descriptive-analytical approach was utilized, and its subjects consisted of (353) individuals working in (31) schools, who were chosen by the simple random method. The finding of the study revealed that there is no significant difference between the perceptions of principals and teachers on teacher accountability. Duggan (2011) aimed to identify the degree of school principals' understanding of the effects of policy on improving school accountability in Australia. The study sample consisted of (14) principals. Data was collected through an interview. The results indicated that the school's self-evaluation is more supportive of improving students' achievement than School review and that there is a relationship between self-evaluation and building school culture in teachers' practices.

In Saudi Arabia, Al-Maliki (2015) conducted a study to measure the degree to which principals of education offices practice educational accountability from the viewpoints of middle school principals in Makkah. The descriptive survey method was adopted. The results showed no statistically significant differences in the degree of education principals' practice of educational accountability attributed to the variable (educational qualification, specialization, and years of service) except for the field of educational accountability in which there were differences attributed to years of service and in favor of 10 years or more.

Eisan \& Kharousi (2016) attempted to determine the administrative accountability requirements for public schools in the Sultanate of Oman. The sample consisted of (171) male and female principals in public schools in the Sultanate of Oman. The tool consisted of (48) items distributed on the dimension of transparency and spreading its culture, and administrative accountability tools and methods, and the terms of the administrative accountability team. The study concluded that the requirements for applying administrative accountability to government schools in the Sultanate of Oman came to a high degree, and there were differences attributed to the academic qualification in the field of the terms of the administrative accountability team in favor of the doctoral and master's qualifications, and there were differences for years of work experience in all the requirements in general and the field of the terms of the administrative accountability team in favor of the most experienced.

In a recent study, Abu Kush et al. (2017) studied the estimation of the degree of administrative accountability of secondary school principals within the Green Line. The study population consisted of all (1826) secondary school teachers in the Negev educational region within the Green Line, where the study sample consisted of (323) male and female teachers. A questionnaire consisting of (24) items was built. The study concluded that the degree of administrative accountability of secondary school principals within the green line was high, and it was found that there was no difference between the averages of the sample responses attributable to gender, educational qualification, and experience. In another recent study, Al-Habil (2017) identified the role of administrative 
accountability at the Internal Control Department in the schools of Gaza Governorate from the point of view of its principals. The researcher indicated that the degree of the practice of the internal control department of administrative accountability in the schools of Gaza Governorate was high and that there were no differences among the participants to the degree of the practice of the internal control department in the schools of Gaza governorate of administrative accountability due to the variables of gender, academic qualification, years of service and educational stage, except for the field of public job ethics. Where it was in favor of the bachelor's degree. It also indicated a positive direct relationship between administrative accountability and the improvement of administrative performance.

Considering the available previous studies related to the topic of research, it was noted that several studies have dealt with the issue of administrative accountability from the educational side, and according to the researcher's knowledge, no studies applied accountability to special education centers in Jordan or abroad. Some studies were conducted to identify the degree of school principals' understanding of administrative accountability from the teachers' point of view, such as the study of (Duggan, 2011; Abu Kush et al., 2017; Ataphia, 2011). Moreover, some studies attempted to measure the practice of educational accountability by the principals from their point of view, such as the study of (Al-Habil, 2017; Eisan \& Kharousi, 2016; Al-Maliki, 2015). As for the method of analysis used in the previous studies, it was noted that all studies used descriptive analysis, except for the study of (Duggan, 2011), which used the interview method to collect information, and the size of the samples in previous studies ranged between (133-353) individuals.

\section{Methods and Procedures}

\subsection{Study approach}

The descriptive-analytical method was utilized as it is an appropriate method for achieving the objectives and addressing the questions of the study.

\subsection{Population and sample}

The study population consisted of all the (185) teachers working in special education centers in Amman. The study sample comprised (92) male and female teachers who were randomly selected from the study population with a percentage of $(50 \%)$ of the study population. 85 questionnaires were distributed retrieved. Table ishows the distribution of the study population and sample.

Table 1: Description of the study population and sample according to its variables

\begin{tabular}{|l|l|c|c|}
\hline Variable & Category & NO. & Ratio \\
\hline \multirow{2}{*}{ Gender } & Male & 37 & $44 \%$ \\
\cline { 2 - 4 } & Female & 48 & $56 \%$ \\
\hline \multirow{3}{*}{ Academic level } & Diploma & 11 & $13 \%$ \\
\cline { 2 - 4 } & Bachelor's & 59 & $69 \%$ \\
\cline { 2 - 4 } & Postgraduate & 15 & $18 \%$ \\
\hline \multicolumn{2}{|l}{ Total } & 85 & $100 \%$ \\
\hline
\end{tabular}

\subsection{Instrument}

The scale was developed based on a set of related studies such as (Al-Zoubi, 2003; Al-Omari, 2004; Abu Hamda, 2008). A measure was developed consisting of (18) items distributed over four fields namely, Students field including (4) statements, Teachers' field (6) statements., Scope of objectives (4) statements and the field of creativity and innovation (4) statements. Teachers at special education centers were asked to answer on items related to the concept of educational administrative 
accountability using a five-point Likert scale as follows: Strongly agree (5) score, agree (4) scores, neutral (3) scores, do not agree / (2) scores, strongly disagree (1) score. All items were formulated positively, and the range for each of the three levels was extracted according to the following equation: (Higher category - lower category)/3, ie $(5-1) /(3)=(1,33)$, and therefore so: from $(1-2.33=a$ low level); (2.34-3.67=a medium level); and (3.68-5=a high level).

\subsubsection{Instrument validity}

Face validity: the questionnaire was presented to a group of experts in the field of special education and educational administration to check the appropriateness and the integrity of its language.

- Internal validity: the correlation coefficients were obtained for each of the fields and with the overall instrument. The correlation coefficients of the items with the overall tool ranged between (0.352- 0.809), and with the domain to which they belong between (0.365- 0.801) (see Table 2).

Table 2: Correlation coefficients between Items and the overall score of the scale and with the fields on the study scale

\begin{tabular}{|c|c|c|c|c|c|c|c|c|}
\hline $\mathbf{N}$ & With tool & With field & $\mathbf{N}$ & With tool & With field & $\mathbf{N}$ & With tool & With field \\
\hline 1 & $.750^{* *}$ & $.532^{* *}$ & 14 & $.774^{*}$ & $.691^{* *}$ & 26 & $.344^{*}$ & $.421^{* *}$ \\
\hline 2 & $.542^{* *}$ & $.418^{*}$ & 15 & $.382^{*}$ & $.431^{*}$ & 27 & $.416^{*}$ & $.442^{*}$ \\
\hline 3 & $.382^{*}$ & $.383^{*}$ & 16 & $.418^{*}$ & $.370^{*}$ & 28 & $.423^{*}$ & $.621^{* *}$ \\
\hline 4 & $.510^{* *}$ & $.345^{*}$ & 17 & $.660^{* *}$ & $.573^{* *}$ & 29 & $.447^{* *}$ & $.472^{* *}$ \\
\hline 5 & $.442^{*}$ & $.672^{* *}$ & 18 & $.526^{* *}$ & $.419^{*}$ & 30 & $.424^{*}$ & $.723^{* *}$ \\
\hline 6 & $.703^{* *}$ & $.365^{*}$ & 19 & $.410^{*}$ & $.524^{* *}$ & 31 & $.809^{* *}$ & $.801^{* *}$ \\
\hline 7 & $.444^{* *}$ & $.575^{* *}$ & 20 & $.380^{*}$ & $.534^{* *}$ & 32 & $.540^{* *}$ & $.375^{*}$ \\
\hline 8 & $.420^{* *}$ & $.533^{* *}$ & 21 & $.539^{* *}$ & $.730^{* *}$ & 33 & $.347^{*}$ & $.439^{* *}$ \\
\hline 9 & $.530^{* *}$ & $.530^{* *}$ & 22 & $.521^{* *}$ & $.612^{* *}$ & 34 & $.510^{* *}$ & $.521^{* *}$ \\
\hline 10 & $.513^{* *}$ & $.533^{* *}$ & 23 & $.630^{* *}$ & $.547^{* *}$ & 35 & $.445^{*}$ & $.630^{* *}$ \\
\hline 11 & $.640^{* *}$ & $.567^{* *}$ & 24 & $.352^{*}$ & $.621^{* *}$ & 36 & $.436^{*}$ & $.367^{*}$ \\
\hline 12 & $.411^{*}$ & $.603^{* *}$ & 25 & $.533^{* *}$ & $.441^{*}$ & 37 & $.496^{* *}$ & $.672^{* *}$ \\
\hline 13 & $.667^{* *}$ & $.532^{* *}$ & & & & & & \\
\hline
\end{tabular}

*Statistically significant at the significance level (0.05) ${ }^{* *}$ Statistically significant at the significance level (o.01).

The correlation coefficients of the items with the total tool and the fields to which it belongs were statistically significant at significance levels $\alpha=(0.05)$ and (0.01), so none of them was deleted, and this indicates that the scale is suitable for measuring the degree of application of educational administrative accountability as it obtains high validity and is deemed appropriate for the current study.

\subsubsection{Scale reliability}

The reliability coefficient was calculated by the internal consistency method according to Cronbach's alpha, and the test-retest reliability of the overall tool. The internal consistency coefficient by the Cronbach alpha method reached (o.84), while the reliability of the test-retest reached (o.82) (see Table 3).

Table 3: The reliability coefficients of the scale (Cronbach's alpha\& test-retest)methods

\begin{tabular}{|c|l|c|c|}
\hline \multicolumn{1}{|c|}{ Domains } & \multicolumn{1}{|c|}{ Fields } & Test-retest & Cronbach's alpha \\
\hline \multirow{4}{*}{ Educational administrative accountability } & Students & 0.83 & 0.85 \\
\cline { 2 - 4 } & Teachers & 0.81 & 0.84 \\
\cline { 2 - 4 } & Objectives & 0.83 & 0.85 \\
\cline { 2 - 4 } & Creativity and innovation & 0.80 & 0.83 \\
\cline { 2 - 4 } & Total & 0.82 & 0.84 \\
\hline
\end{tabular}


The results indicate that the reliability coefficients of the current study are high and acceptable for its purposes, and this supports the use of this scale in the current study.

\subsection{Statistical analysis:}

The EXCEL program was utilized in the process of data entry and unloading, and the Statistical Package for Social Sciences (SPSS) program was used in various statistical analyses. The statistical methods that were used to examine the study questions are as follows:

1. Means, standard deviations, and percentages.

2. Pearson correlation coefficient test and simple regression equation.

3. Two-way ANOVA analysis.

\section{Results and Discussion}

\subsection{Results of the first question}

What is the degree of application of educational administrative accountability by the principals of special education centers from the teachers' perspective? Descriptive analysis was used. The means, ranks, standard deviations, and scores of the participants' responses to fields of educational administrative accountability were calculated as shown in Table 4.

Table 4: Descriptive analysis of the Educational Administrative Accountability Scale

\begin{tabular}{|c|l|c|c|c|c|}
\hline $\mathrm{N}$ & \multicolumn{1}{|c|}{ Field } & Mean & Rank & St. & Degree \\
\hline $\mathbf{1}$ & Students & 3.65 & 2 & .732 & medium \\
\hline 2 & Teachers & 3.63 & 3 & .574 & medium \\
\hline 3 & Objectives & 3.66 & 1 & .613 & high \\
\hline 4 & Creativity and innovation & 3.48 & 4 & .627 & medium \\
\hline \multicolumn{2}{|c|}{ Total } & 3.63 & .675 & medium \\
\hline
\end{tabular}

The means of the fields ranged between (3.48-3.66) and they obtained medium levels except for the field "objectives" which obtained a high mean of (3.66) and a standard deviation (.613). The "Students" field ranked second with a mean of (3.65), followed by the field "teachers" with a mean of (3.63). While the field of "creativity and innovation" came in the last place with a mean of (3.48). The overall mean of administrative accountability in educational systems is (3.63) with a standard deviation of (.675) and at a medium level.

The researcher deemed this result as a logical output as administrative accountability in educational systems is a means of following up on the work of subordinates, an entrance to ascertain how actual performance and the formation of ideas on how to perform appropriately, as it sheds light on any defect that the institutions suffer from, as it provides us with the true image of the system (Kahala \& Radwan, 2002). Furthermore, it works to activate the responsibility of the individuals working in this system by dealing transparently with all the components of the system and its performance. Researchers consider that the principal is the key to the effectiveness of the school because under his position he is expected to provide high educational service and achieve rates of coordinating interdependence among the staff to raise and improve the educational process and develop general performance and educational goals.

This result is also due to the extent to which the principals of special education centers are aware of the importance of educational goals in the educational system and their connection to the reality of implementing activities in the centers and to the need to keep pace with educational goals for scientific progress in the light of contemporary educational trends. It also attributed to their awareness of the need for educational evaluation methods that measure the performance of students 
and teachers to increase according to specific criteria, and the need to adopt the principle of participation of teachers in the educational system to determine educational evaluation methods. This result is consistent with the results of (Abu Kush, et al 2017; Al-Maliki, 2015; Duggan 2011; Ataphia, 2011).

\subsection{Results of the second question}

Are there statistically significant differences in the degree of application of educational administrative accountability by the principals of special education centres attributed to the variables gender and educational level? To address this question, the means and standard deviations of the participants' responses were calculated according to the gender variable and the educational level, as shown in Table 5 .

Table 5: Means of the variable of gender and educational level

\begin{tabular}{|l|l|l|l|l|c|}
\hline \multicolumn{2}{|c|}{ Variables } & N & Mean & St. & Rank \\
\hline \multirow{3}{*}{ Gender } & Male & 37 & 3,76 & 48. & 2 \\
\cline { 2 - 6 } & Female & 48 & 3,95 & 43. & 1 \\
\hline \multirow{3}{*}{ Academic level } & Diploma & 11 & 3,27 & .76 & 3 \\
\cline { 2 - 6 } & Bachelor's & 59 & 3,88 & .46 & 1 \\
\cline { 2 - 6 } & Postgraduate & 15 & 3,59 & .53 & 2 \\
\hline
\end{tabular}

Table (5) shows few differences attributable to the gender variable, the male category obtained the lowest mean (3.76), while the female category obtained the highest mean (3.95). Regarding the educational level variable, individuals with bachelor's degrees obtained the highest mean (3.88), followed by the postgraduate category with a mean (3.59), whereas the diploma holders got a mean of (3.27). To check the statistical significance of the differences between the means in the degree of application of educational administrative accountability by the principals of the special education centers in the study sample, the test was conducted with a two-way ANOVA analysis (see Table 6).

Table 6: Results of ANOVA analysis according to gender \& academic level

\begin{tabular}{|l|c|c|c|l|l|}
\hline The degree of application of educational administrative accountability & SS & Df & MS & F value & P value \\
\hline Gender & 0,358 & 1 & 0,219 & 0,595 & 0,127 \\
\hline Academic level & 0,561 & 2 & 0,162 & 0,671 & 0,348 \\
\hline
\end{tabular}

There are no statistically significant differences at the level of significance $(\alpha=0.01)$ in the degree of application of educational administrative accountability by the principals of special education centers attributable to the gender variable. Data in Table (6) also revealed no significant differences at the level of statistical significance in the degree of application of educational administrative accountability due to academic level. This result may be attributed to the fact that gender and academic qualification do not impact the participants' awareness of the importance of applying educational administrative accountability by the principals of special education centers, and that they are more willing to accept educational accountability in the educational system regardless of their social gender or their educational level. It is also due to the fact that both male and female principals are aware of the reality of their role and what is expected from them when performing the entitled duties appropriately regardless of their academic qualifications and that they are affected by the same level of this role. Besides, the dissimilarity in social conditions in terms of gender between male and female teachers may generate a difference in capabilities, nature, goals, and their constant quest to develop their skills and abilities. 


\section{Conclusions \& Recommendations}

Considering the findings of the current study, it recommends the following:

1. Activating the function of various media in the dissemination process to spread and deepen a positive understanding of the culture of educational administration responsibility.

2. Issuing guides and awareness-raising publications on the concepts of administrative accountability in the educational field and setting laws and regulations to control administrative shortcomings and their misuses in special education centers and institutions, with the need to update them according to developments that occur in society, whether at the local or international levels.

3. Holding seminars, lectures, and meetings to present educational accountability principles, strengthen such ideas, improve their application, and enact processes to make them a key component of the educational system.

\section{References}

Abu Al-Wafa, J. (2008). School and Classroom Administration, New University House, Alexandria, Egypt.

Abu Hamda, S. A. (2008). The degree of application of administrative accountability and its relationship to the level of job satisfaction for teachers at private secondary schools in the capital, Amman, from their point of view, an unpublished MA thesis of the Middle East University for Graduate Studies.

Abu Kush, S. J., Sharman, M. M. \& Al-Barakat, A. A. (2017) The degree of application of administrative accountability for secondary school principals within the Green Line, Journal of the Islamic University for Educational and Psychological Studies, Volume (26), Issue (4), pp. 528-846.

Akhuirsheed, A. (2006). Accountability and Effectiveness in Educational Administration, Amman, Jordan, AlHamed Library House.

Al-Habil, R. M. (2017). The Role of Administrative Accountability at the Internal Control Department and Its Relation to Improving Administrative Performance in Gaza Governorate Schools, Unpublished Master Thesis, Islamic University - Gaza.

Ataphia, D. (2011). An Assessment of Accountability among Teachers in Secondary Schools in Delta State. African Journal of Social Sciences, Vol.1(1), pp.115-125.

Batah, A. (2006). Contemporary Issues in Educational Administration, Amman, Jordan, Al-Shorouk Publishing and Distribution House.

Al-Derini, L. (200o). Attitudes of secondary school principals towards in the Capital Governorate, an unpublished master's thesis, University of Jordan, Amman: Jordan.

Duggan, M. (2011). School accountability in the Western Australian public-school sector: Perceptions of leaders in the field. MA. Thesis. Murdoch University, Perth Western, Australia.

Eisan, S., and Kharousi, S. (2016). Requirements for applying administrative accountability to public schools in the Sultanate of Oman from the point of view of their principals, Journal of Educational and Psychological Sciences, Sultan Qaboos University, Sultanate of Oman, Volume (2), Issue (17), pp. 45-80.

Fillet, F. A., \& Abdul Majeed, M. (2005). Organizational behaviour in the management of educational institutions, (1), Dar Maisarah for Publishing and Distribution, Amman, Jordan.

Fort, E., \& Hebbler, S . (2004). A Framework for Examining Validity in State Accountability Systems, Washington; Council of Chief State School Officers.

Al-Hammoud, L. (2007). A proposed model for accountability at the level of the Jordanian public secondary school in light of contemporary administrative trends, unpublished PhD thesis, Amman Arab University, Amman, Jordan.

Al-Harith, Y. S. A. (2005). Attitudes of primary school principals in the Hail region towards the reality of practising accountability in educational administration in the Kingdom of Saudi Arabia, an unpublished master's thesis, University of Jordan, Amman, Jordan.

Hwail, I. M. (2012). The reality of implementing educational accountability and overall quality and the relationship between them in UNRWA schools in the West Bank from the point of view of administrators in it, an unpublished master's thesis, An-Najah National University, Nablus, Palestine.

Kaspari, A. E. (2003). Attitudes of secondary school principals towards accountability in educational administration in the governorates of the northern West Bank, an unpublished master's thesis, An-Najah National University, Nablus, Palestine. 
Kahala, G., \& Radwan. H. (2002) Introduction to Responsibility Accounting and Performance Evaluation, House of Science and House of Culture for Publishing and Distribution, Amman, Jordan.

Khatib, A., Al-Zaabi, S. \& Abdel-Rahman, M. (2013). The level of effectiveness of the institutions and centres of special education dealing with autism in Jordan according to international standards, Journal of Al-Quds Open University for Research and Educational and Psychological Studies, Volume (1), Issue (4), pp. 394-425.

Madaus, G.F (200o). Educational Accountability. ERIC, ED.

Al-Maliki, J, H, K. (2015) The degree to which directors of education offices practice educational accountability from the point of view of middle school principals in Makkah Al-Mukarramah. A magister message that is not published. Umm Al-Qura University, Kingdom of Saudi Arabia

Al-Omari, H. M. B. (2012). The degree of availability of educational accountability elements in the educational accountability system in the Ministry of Education in Jordan, Journal of the Association of Arab Universities for Education and Psychology, Volume (10), Issue (1), pp. 71-98.

Al-Omari, K.(2004). Accountability and educational reform in the framework of the systemic approach, a paper presented to the Arab Conference on Systemic Approach to Teaching in Teaching and Learning, April 3-4, Ain Shams University, Cairo, Egypt.

Al-Rasbi, Z. N. (2006). Development of a Performance Accountability Model in the Education System in the Sultanate of Oman, unpublished PhD thesis, University of Jordan, Jordan.

Tarkhan, M. (2006), Accountability, its concept, types, and applications in modern school administration, UNRWA, Department of Education, Institute of Education, Amman, Jordan.

Al-Taweel, H. (2006). Educational Administration and Organizational Behavior - Individual and Group Behavior in Systems, Wael Publishing House, Amman, Jordan.

Al-Taweel, H. (1999). Educational administration concepts and prospects. Wael Publishing House, Amman, Jordan.

Thabet, Adel (2008). Contemporary Management Psychology, Amman, Jordan, House of Culture for distribution.

Touq, M. (1997). Accountability and Democracy, an unpublished working paper submitted to the Accountability Conference, Amman, Jordan.

\section{Appendix 1: The Study instruments}

\begin{tabular}{|c|c|c|c|c|c|}
\hline Fields: Students & $\begin{array}{c}\text { Strongly } \\
\text { agree }\end{array}$ & Agree & Neutral & Disagree & $\begin{array}{l}\text { Strongly } \\
\text { disagree }\end{array}$ \\
\hline 1 Accountability helps monitor educational programs & & & & & \\
\hline 2 It helps the teacher make effective use of the textbook & & & & & \\
\hline 3 Teacher accountability guides the use of teaching aids & & & & & \\
\hline $4 \begin{array}{l}\text { It works to create an atmosphere of trust between the principal and } \\
\text { teachers to develop proposals for the curriculum }\end{array}$ & & & & & \\
\hline Teachers & & & & & \\
\hline $\begin{array}{ll}1 & \text { It leads to teacher discipline in special education centres }\end{array}$ & & & & & \\
\hline 2 It promotes the teacher focus on student performance & & & & & \\
\hline $3 \begin{array}{l}\text { Creates an atmosphere of trust between the teachers and the } \\
\text { principal }\end{array}$ & & & & & \\
\hline 4 Motivating teachers for professional development & & & & & \\
\hline 5 Increase competition among teachers & & & & & \\
\hline 6 It encourages doing action research & & & & & \\
\hline Objectives & & & & & \\
\hline $\begin{array}{l}1 \text { It aims to limit the director's independence and freedom to use his } \\
\text { authority }\end{array}$ & & & & & \\
\hline 2 Aiming to improve the quality of education & & & & & \\
\hline $\begin{array}{l}\text { It aims to keep pace with education with technological } \\
\text { development }\end{array}$ & & & & & \\
\hline 4 It aims to identify the needs of schools & & & & & \\
\hline Creativity and Innovation & & & & & \\
\hline 1 It contributes to stimulating the creative thinking of the manager & & & & & \\
\hline 2 It contributes to stimulating the creative thinking of teachers & & & & & \\
\hline $\begin{array}{l}3 \begin{array}{l}\text { It keeps pace with the latest developments in special education and } \\
\text { adopts them }\end{array}\end{array}$ & & & & & \\
\hline 4 It contributes to stimulating creative thinking among students & & & & & \\
\hline
\end{tabular}

